\title{
A NOTE ON STRONG LAW OF LARGE NUMBERS
} FOR DEPENDENT RANDOM SEQUENCE

\author{
WANG ZHONG-ZHI AND YANG WEI-GUO
}

Abstract. This note is devoted to establish a general strong law of large numbers for dependent random variables. As corollaries, we generalized some known results.

Mathematics subject classification (2010): 60F15.

Keywords and phrases: Random variable, strong law of large numbers, dominated random sequence.

\section{REFERENCES}

[1] R. JAJTE, On the strong law of large numbers, The Annals of Probability. 31, (2003), 409-412.

[2] M. Loeve, Probability Theory (II), Springer-Verlag, New York, 4th edition, 1978.

[3] Y. AdLER, A. RosASKY, Some general strong laws for weighted sums of stochastically domainated random variables, Stochastic Analysis and Application, 5 (1), (1987), 1-16.

[4] Y. S. Chow, H. TeICher, Probability Theory, Springer-Verlag, New York Inc, 1978.

[5] W. F. Stout, Almost sure convergence, Academic Press, 1974. 